\title{
Effect of gum arabic coating combined with calcium chloride on physico-chemical and qualitative properties of mango (Mangifera indica L.) fruit during low temperature storage
}

\begin{abstract}
Effect of gum arabic (GA) $10 \%$ and calcium chloride (CA) $3 \%$ on the physiological and biochemical properties of mango (Mangifera indica L. CV. Choke Anan) fruits stored at $6 \pm 1$ ${ }^{\circ} \mathrm{C}$ and $90 \pm 3 \%$ relative humidity for 28 days and then transferred to $25 \pm 2{ }^{\circ} \mathrm{C}$ for 5 days shelf life were investigated. Significant (P Ò0.05) differences were observed in fruits treated with GA $10 \%$ and CA $3 \%$ as compared to control. The combined treatment of CA $3 \%+$ GA $10 \%$ significantly alleviated the increase in decay incidence. Furthermore, GA $10 \%$ alone or combined with CA 3\% effectively reduced weight loss, color changes, soluble solid concentration, respiration rate, ethylene production and maintained high firmness, titratable acidity and ascorbic acid. The result of transmission electron microscopy revealed that these treatments also protected the ultrastructure of mitochondria. These results suggest that application of GA $10 \%$ coating combined with CA $3 \%$ might be a simple and effective technique for preserving mango fruit quality during low temperature storage.
\end{abstract}

Keyword: Mango; Gum arabic; Calcium chloride; Low temperature; Postharvest qualities; Ultrastructural changes 